\title{
Práticas avaliativas na educação física escolar: um estudo com professores de Miracema do Tocantins (T0)
}

\author{
Evaluative practices in school physical education: \\ a study with teachers from Miracema do Tocantins (TO), Brazil
}

\section{Marciel Barcelos}

Universidade Federal do Tocantins (UFT), Miracema/TO, Brasil

\section{HISTÓRICO DO ARTIGO \\ Recebido: 01 maio 2020 \\ Revisado: 05 junho 2020 \\ Aprovado: 22 junho 2020}

\section{PALAVRAS-CHAVE:}

Avaliação; Aprendizagem; Educação Física.

\section{KEYWORDS:}

Assessment; Learning;

Physical Education.

\section{RESUMO}

OBJETIVO: O foco desta pesquisa foi compreender quais práticas avaliativas têm sido mobilizadas na educação física escolar no município de Miracema do Tocantins (TO).

MÉTODOS: A pesquisa configura-se como um estudo de caso e utilizou como instrumento de produção de fontes um questionário estruturado e aplicado junto a cinco professores com formação em educação física do município de Miracema do Tocantins (TO). Os dados produzidos foram organizados por meio do software SPSS, v. 20.0, apresentados em forma de quadros. Utilizou-se a literatura sobre avaliação para aprendizagem na análise de dados.

RESULTADOS: O estudo sinalizou o movimento auto formativo dos professores no tocante a avaliação para aprendizagem, bem como a dificuldade em compreender quais os objetivos que devem ser avaliados. Também sinalizou a utilização de práticas avaliativas associadas com a perspectiva da medida e em menor quantidade aquelas pautadas no protagonismo dos alunos.

CONCLUSÃO: Conclui-se que os docentes pesquisados mobilizaram uma variedade de práticas avaliativas para aprendizagem na educação física escolar, contudo privilegiaram o aprendizado sobre o conteúdo em detrimento do fazer corporalmente.

\section{ABSTRACT}

OBJECTIVE: The focus of this research was to understand which evaluative practices have been mobilized in school physical education in the municipality of Miracema do Tocantins (TO), Brazil.

METHODS: The research is configured as a case study and used as a source production tool a structured questionnaire applied to five teachers with training in physical education in the municipality of Miracema do Tocantins (TO), Brazil. The data produced was organized using the SPSS 20.0 software. presented in the form of tables. Literature on assessment for learning in data analysis was used.

RESULTS: The study signaled the teachers' self-training movement with regard to assessment for learning, as well as the difficulty in understanding which objectives should be assessed. It also signaled the use of evaluative practices associated with the perspective of the measure and to a lesser extent those based on the protagonism of the students.

CONCLUSION: It is concluded that the researched teachers mobilized a variety of evaluative practices for learning in physical education at school, however they favored learning about content rather than doing bodily. 


\section{INTRODUÇÃO}

O objetivo desse trabalho é compreender quais práticas avaliativas têm sido mobilizadas na educação física escolar no município de Miracema do Tocantins (TO). Essa intencionalidade emerge na medida em que compreendemos que a avaliação tem papel fundamental na prática pedagógica dos professores na escola, sua ação é o fio condutor do trabalho docente permitindo o diagnóstico daquilo que o aluno sabe, do que aprendeu, como aprendeu e, mais do que isso, como usou aquilo que aprendeu (SANTOS et al., 2019; LANO, 2019).

É importante destacar que os estudos sobre avaliação para aprendizagem têm aumentado no Brasil, especialmente a partir da década de 2000 (FROSSARD, 2015; SANTOS et al., 2018). Esse cenário permitiu ao campo científico apontar diferentes discursos sobre a avaliação no contexto nacional (MENDES; BARBOSA-RINALDI, 2020). O próprio estudo de Santos (2005) que sinalizou o uso de diferentes possibilidades avaliativas na educação física escolar por meio da avaliação indiciária contribui para esse entendimento, avançando ao propor práticas que privilegiam a compreensão dos aprendizados a partir da especificidade da educação física.

A avaliação indiciária (SANTOS, 2005) tem apontado o uso (CERTEAU, 1994) ${ }^{1}$ de registros imagéticos, narrativas orais e escritas, fichas avaliativas produzidas por professores e alunos e o portfólio como práticas avaliativas que escapam de uma tradição escolar de avaliação e que possibilitam aos docentes e discentes, potencializar o protagonismo no processo de escolarização.

Nessa perspectiva avaliativa, o aluno é colocado como protagonista do seu processo avaliativo (e formativo), ao mesmo tempo em que permite, ao docente, analisar suas próprias práticas (VIEIRA, 2018; LANO, 2019). Dessa maneira, forma-se uma ação de coparticipação entre professor e aluno no processo de ensino e aprendizagem (LANO, 2019).

Retomando a discussão sobre o campo científico, chamamos atenção para o estudo de Frossard (2015) e Santos et al. (2018). Ambos autores destacaram que as produções científicas sobre avalição na educação física de 1930 a 2014 sinalizam como lacuna, a ausência de estudos mapeados sobre avaliação para aprendizagem na região Norte $^{2}$ do país, bem como nas comunidades quilombolas, na educação indígena e na Educação de Jovens e Adultos.

Assim, essa pesquisa insere-se nesse esforço para compreender como o processo avaliativo na educação física escolar ocorre em um município do estado do Tocantins.

Essa pesquisa, permite a comunidade científica um primeiro olhar sobre aquilo que ocorre no estado mais jovem da federação, em particular as práticas avaliativas em mobilização na educação física escolar. Haja vista que nos estudos de mapeamentos realizados, tanto na área da educação (POLTRONIERI; CALDERÓN, 2012; VIEIRA, 2019) como na área da educação física (FROSSARD, 2015; SANTOS et al. 2018), como dito anteriormente, não foram captados estudos produzidos

Para Certeau (1994) os praticantes do cotidiano usam aquilo que Ihes é oferecido para produzir suas proprias intencionalidades, com o intuito de realizar um movimento que possa subverter as lógicas de um determinado lugar para atender as suas demandas.

2 A região norte do Brasil é composta pelos seguintes estados: Amazonas, Amapá, Acre, Roraima, Rondônia, Pará e Tocantins. nesse estado, evidenciando a emergência de produção científica especializada na região.

\section{MÉTODOS}

O estudo, de natureza qualitativa, utiliza como método o estudo de caso (MICHEL, 2015). Ele nos permite compreender um fenômeno ocorrido em contexto específico. O estudo em questão objetiva compreender a avaliação para aprendizagem na educação física escolar de Miracema do Tocantins (TO).

Compartilhamos das considerações de Oliveira (2013) ao destacar que pesquisas realizadas em escolas se configuram como uma possibilidade de análise de uma cultura escolar e, especialmente, das complexas redes de colaboração existentes entre os docentes. Isso tensiona a maneira como o processo de escolarização é desenvolvida e projetam as vidas dos alunos matriculados nas instituições educacionais.

Nosso instrumento de produção de fontes foi um questionário estruturado (MICHEL, 2015) cujas as intencionalidades foram: a) compreender a apropriação do debate em torno da avaliação para aprendizagem na formação inicial, b) o que é avaliado pelos docentes durante suas aulas, c) e sobre as práticas avaliativas mobilizadas por eles. A partir desses eixos, elaboramos as questões com o intuito de gerar tabelas que nos auxiliam na discussão dos dados.

É importante destacar que a teorização de Certeau (1994) nos orienta nessa pesquisa e, por meio dela, consideramos os participantes como praticantes, pois entendemos que eles agem no cotidiano escolar usando tudo aquilo que lhes é ofertado.

Os praticantes foram professores com formação em educação física que atuam na rede de ensino de Miracema do Tocantins (TO), no ensino fundamental anos finais, para tal, utilizamos os seguintes critérios de inclusão: possuir licenciatura em educação física; trabalhar nas escolas municipais ou estaduais do município de Miracema do Tocantins (TO); atuar no ensino fundamental anos finais; e exclusão: não possuir formação em educação física; possuir somente o magistério; ter formação em outra área de atuação docente e completar carga horária no componente curricular educação física,

O emprego de critérios de inclusão e exclusão foram importantes, uma vez que neste município há falta de docentes para determinados componentes curriculares, dessa forma, há um quantitativo significativo de docentes que não possuem formação específica e, por isso, atuam em áreas do conhecimento diversas nas escolas municipais e estaduais, inclusive no componente educação física, para mitigar o prejuízo de déficit docente na região norte.

Esse estudo está abrigado no âmbito do projeto de pesquisa "Avaliação para aprendizagem na educação básica" registrada no Conselho de Ética da Fundação Universidade Federal do Tocantins (CAAE: 14767419.9.0000.5519), aprovada no Parecer $\mathrm{n}^{\circ}$. 3.678.143. A partir desse movimento e do emprego dos critérios supracitados, foram selecionados oito professores com formação em educação física. Desse total, cinco professores responderam o questionário no prazo proposto e se constituem como os participantes da pesquisa.

É importante destacar que o município de Miracema do 
Tocantins (TO) ${ }^{3}$ possui três escolas de ensino fundamental anos finais no perímetro urbano, que funcionam nos turnos matutino e noturno. ${ }^{4}$

Sistematizamos no Quadro 1, a seguir, o nível de formação, natureza e experiência dos professores com formação em educação física que participaram da pesquisa.

Quadro 1. Professores com formação em educação física participantes da pesquisa.

\begin{tabular}{|cccc|}
\hline Professor & $\begin{array}{c}\text { Nível de } \\
\text { Formação }\end{array}$ & $\begin{array}{c}\text { Natureza da } \\
\text { IES }^{5}\end{array}$ & $\begin{array}{c}\text { Tempo de } \\
\text { Experiencia }\end{array}$ \\
\hline P1 & Superior completo & Particular & 2 messes \\
\hline P2 & Superior completo & Pública estadual & 12 anos \\
\hline P3 & Superior completo & Pública federal & 3 anos \\
\hline P4 & Pós-graduação lato-sensu & Particular & 10 anos \\
\hline P5 & $\begin{array}{l}\text { Superior completo e } \\
\text { pós-graduação lato-senso }\end{array}$ & Pública estadual & 31 anos \\
\hline
\end{tabular}

Fonte: Elaboração própria.

A partir das fontes, produzidas por meio do questionário, realizamos um recorte para dar visibilidade a três temáticas, são elas: a) avaliação e formação inicial; b) o que os docentes avaliam e c) práticas avaliativas. Os dados foram organizados no software IBM SPSS (Statistical Package for the Social Sciences), v. 20.0, de onde transformamos em tabelas para melhor compreensão dos resultados.

No item "a" discutiremos sobre a apropriação da avaliação para aprendizagem no curso de formação de professores, no item " $b$ " discutiremos o que os docentes avaliam nas aulas de educação física e no item " $c$ " sobre as práticas avaliativas mobilizadas por eles e suas concepções.

\section{RESULTADOS}

Avaliação para aprendizagem no ensino fundamental anos finais de Miracema do Tocantins: da formação às práticas avaliativas

A primeira discussão do estudo se refere a formação inicial em educação física, analisamos se os docentes tiveram alguma orientações sobre avaliação para aprendizagem.

O Quadro 2 foi produzido por meio de perguntas em que os docentes concordavam ou discordavam da questão de acordo a sua trajetória profissional. A questão era: “Em relação ao seu aprendizado sobre avaliação para aprendizagem, sinalize sim ou não para as questões de acordo com a sua trajetória profissional".

Evidenciamos que o item "formação inicial", foi assinalado pela maior parte dos professores, indicando que aquele é o lugar privilegiado de compreensão/aprendizado sobre o fazer docente em relação a avaliação. De acordo com Vago (2009), a formação inicial altera e reforça as ações dando direcionamentos teóricos

${ }^{3}$ De acordo com dados do Instituto Brasileiro de Geografia e Estatística - IBGE, a população estimada da cidade é de 18.248 mil habitantes, sendo a 139 o cidade mais populosa do Tocantins. A cidade .

Em função das condiç̃ões climáticas do estado do Tocantins, não há aulas no período vespertino em diversas cidades, Miracema do Tocantins (TO) é uma delas, ofertando o turno matutino e noturno, períodos do dia em que as temperaturas variam entre $27^{\circ}$ e $33^{\circ}$ graus.

${ }^{5}$ Instituição de Ensino Superior. e práticos. Na licenciatura as discussões sobre avaliação são acompanhadas do próprio fazer docente daquele que conduz a formação em nível superior, isso, de acordo com Vago (2009), impacta na maneira como os futuros profissionais atuarão no cotidiano escolar, especialmente no desenvolvimento de práticas avaliativas.

Quadro 2. Sobre a trajetória profissional e os estudos sobre avaliação para aprendizagem na educação física escolar.

\begin{tabular}{|lcc|}
\hline Descrição & Sim & Não \\
\hline Na minha formação inicial & 4 & 1 \\
\hline Por iniciativa própria & 4 & 1 \\
\hline $\begin{array}{l}\text { Em congressos seminários ofertados por universidades ou outros } \\
\text { órgãos }\end{array}$ & 3 & 2 \\
\hline $\begin{array}{l}\text { Na escola que atuo, em conversas com pedagogos nos planeja- } \\
\text { mentos e reuniões coletivas com outros professores da escola }\end{array}$ & 3 & 2 \\
\hline $\begin{array}{l}\text { Em formação continuada ofertada pelas secretarias municipais ou } \\
\text { estaduais de educação }\end{array}$ & 2 & 3 \\
\hline $\begin{array}{l}\text { Fonte: Elabora própria. } \\
\text { Fon }\end{array}$ & & \\
\hline
\end{tabular}

O segundo item com maior recorrência no Quadro 2, indicou que os docentes recorrem a "iniciativa própria" para produzir a avaliação para aprendizagem na educação física escolar o que, também, se aproxima do terceiro item com maior recorrência que é o movimento autoformativo realizado na "conversas entre pares".

Vieira (2018) ao dar visibilidade a uma proposta de avaliação para aprendizagem no ensino fundamental, sinalizou como os docentes recorrem as suas experiências particulares e dos outros (CHARLOT, 2000) para produzir práticas pedagógicas, em um movimento de apropriação (CERTEAU, 1994) ${ }^{6}$ daquilo que atravessa seu cotidiano.

Nesse caminho, a autora, destaca que por vezes aquilo que o docente faz pode ser compreendido como avaliação, mas para isso é preciso entendê-la como ação formativa e processual e que deve orientar não só o olhar do professor, mas também de alunos, permitindo o enriquecimento dos saberes compartilhados (VIERA, 2018) entre eles em um movimento de coparticipação (LANO, 2019).

As perguntas "Em congressos seminários ofertados por universidades ou outros órgãos" e "Em formação continuada ofertada pelas secretarias municipais ou estaduais de educação", a primeira com 3 e a segunda com 2 recorrências, sinalizam que esse movimento formativo é amplo e, também, conta com a mobilização do poder público por meio da Universidade e da própria secretaria municipal de educação.

É importante destacar o movimento tático (CERTEAU, 1994) realizado pelos docentes na busca da qualificação do fazer avaliativo no cotidiano escolar. Santos (2005), Vieira (2018) e Lano (2019) destacaram a necessidade de ampliar as discussões sobre o fazer avaliativo na formação inicial, haja vista que ela contribui não só como arcabouço de práticas avaliativas, mas também para compreensão de diferentes modos de projetar a ação docente por meio de feedback (BLACK; WILIAM, 2003) produzidos pelos alunos em processo de escolarização. Assim, esse debate colabora na compreensão do ato de reorganizar

${ }_{6}$ Para Certeau (1994) nos apropriamos daquilo que atravessa nosso cotidiano e, a partir dessa apropriação, construímos novas maneiras de agir frente aos desafios que se apresentam. 
as práticas pedagógica em direção a melhora da qualidade do ensino.

$\mathrm{Na}$ medida em que compreendemos quais as fontes utilizadas para entender a construção do saber docente sobre avaliação, nos dedicamos a analisar "o quê" os docentes avaliam em suas aulas. No Quadro $3^{7}$, a seguir, cada docente só poderia marcar uma opção. A pergunta era: "O que você avalia em seus alunos?" a intencionalidade era analisar aquilo que os professores com formação em educação física consideram relevantes.

Quadro 3. O que é avaliado na educação física escolar.

\begin{tabular}{|lc|}
\hline Descrição & $\mathbf{n}$ \\
\hline $\begin{array}{l}\text { Avaliar o envolvimento e a apropriação das dimensões culturais e das } \\
\text { práticas corporais; }\end{array}$ & 2 \\
\hline Avaliar os valores (respeito, cooperação e etc.); & 2 \\
\hline Avaliar o conhecimento histórico de um determinado conteúdo. & 1 \\
\hline Fonte: Elaboração própria.
\end{tabular}

O Quadro 3, a opção "o envolvimento e a apropriação das dimensões culturais e das práticas corporais" foi marcada por 2 docentes. Essa resposta revela os sentidos que eles atribuem a própria educação física, colocando-a dentro do escopo da cultura, entendendo seus objetos de ensino como construções sociais, que são reconstruídas no tempo e nos espaços escolares, como fenômenos sociais.

Avaliação, nessa perspectiva, privilegia os saberes objeto e de domínio (CHARLOT, 2000). Para Charlot (2000), os saberes objetos são aqueles materializados nas escolas, por meio de livros, anotações e objetos diversos de apoio didático-pedagógico. Neles, os alunos precisam se apropriar cognitivamente para dar sentido ao seu uso, já os saberes de domínio, são apropriados corporalmente, pela aprendizagem de uma tarefa ou prática corporal.

Schneider e Bueno (2005) destacam que a educação física, embora conectado com o saber de domínio (CHARLOT, 2000) também se vale dos saberes objetos, na medida em que são necessários não só o saber fazer, mas também um saber sobre esse fazer.

A produção das práticas avaliativas nesse sentido, perpassam pela preocupação daquilo que se ensina e como se ensina, colocando a intencionalidade do fazer avaliativo incorporada a própria compreensão do docente sobre o que é importante no aprendizado de um objeto de ensino da educação física escolar (LANO, 2019).

Chamamos atenção para a segunda resposta, que também foi marcada por dois docentes. Ela dá visibilidade ao ensino dos valores. Santos et al. (2019) destacam que, por vezes, os professores com formação em educação física centralizam a avaliação nos valores e assiduidade. Nesse caminho, colocam em segundo plano o próprio objeto de ensino desse componente curricular e as diversas possibilidades de sua mobilização no cotidiano escolar.

Foscarini e Fonseca (2010) ponderam em seu estudo que embora os conhecimentos pertinentes a um conteúdo sejam avaliar a autonomia do processo formativo; todas as anteriores. observados pelos professores entrevistados como objeto da avaliação, eles ponderam que o mesmo não tem peso na atribuição da nota, mas sim a participação nas aulas, reforçando um olhar que desloca o fazer avaliativo do processo de ensinoaprendizagem para um lugar onde se assume como prática de domínio do comportamento dos alunos no cotidiano escolar.

Para além disso, centralizar avaliação no campo dos valores pode fazer com que o professor utilize práticas avaliativas que não consideram o percurso formativo e, tampouco fortaleça uma ação relevante nas discussões em torno da escolarização da educação física, que é a compreensão daquilo que o aluno faz com o que aprende (SANTOS, 2005; SANTOS et al., 2015; 2019; VIERA, 2018; LANO, 2019).

Somente um docente marcou a opção que sinaliza a avaliação dos "conhecimentos históricos." É interessante perceber esse movimento tímido, na medida em que o impacto da produção acadêmica sobre educação física a partir dos anos 1990 tem sido pautado pela análise dos fenômenos esportivos em uma perspectiva cultural (CAPARRÓZ, 1997).

As ações táticas (CERTEAU, 1994) dos docentes sobre o que avaliam, demonstram que há uma divisão na rede municipal de educação de Miracema do Tocantins (TO) sobre os objetivos que devem ser avaliados. $\mathrm{Na}$ análise do documento norteador para o ensino fundamental anos finais (TOCANTINS, 2000) percebemos que a parte dedicada a educação física, a palavra "avaliação" não é citada, embora haja um movimento de municiar os docentes com objetivos a serem alcançados e dicas de atividades, assumindo a perspectiva do tipo "caixa de ferramentas" (BOLZAN; SANTOS, 2015).

Nessa perspectiva, os documentos norteadores configuramse como um suporte pedagógico que objetiva modificar ou subsidiam aquilo que ocorre no cotidiano escolar, configurandose como manuais. Bolzan e Santos (2013) destacam que essa perspectiva de documento, que se assemelha a um livro didático tem como intencionalidade indicar um caminho a ser seguido pelos docentes, definido o projeto de formação daquela rede.

Nesse sentido, sinalizamos a necessidade de formações continuadas que discutam o tema avaliação para aprendizagem na educação física escolar em Miracema do Tocantins (TO), com o intuito de melhorar a compreensão daquilo que precisa ser avaliado, bem como articular os saberes dos docentes aos documentos oficiais da rede de ensino.

É importante destacar a compreensão de Vago (2009) sobre a escola. Para o autor, ela é um lugar de criação, de reinvenção, de usufruir e de vivenciar diferentes culturas e práticas. Pensando nisso, a educação física não deve ser um limitador da avaliação educacional, mas sim, um estímulo para novas possibilidades de práticas avaliativas, recorrendo não só a formação inicial, mas a própria análise daquilo que os alunos fazem no cotidiano para, assim, transformar em avaliação.

Vago (2009) nos permite compreender que a formação inicial, e a clareza sobre o que se avalia, têm impactos nas práticas avaliativas que serão mobilizadas na escola. E, na medida em que compreendemos onde os professores buscam subsídios para fundamentar sua prática avaliativa e aquilo que eles avaliam em suas aulas, passamos a nos dedicar a analisar de quais práticas avaliativas são usadas por elas na escola.

O Quadro 4, a seguir, sinalizamos quais práticas avaliativas 
os professores com formação em educação física utilizam no cotidiano escolar. Na pergunta, o docente poderia escolher mais de uma questão e a pergunta era: quais práticas avaliativas você utiliza em suas aulas?

Quadro 4. Práticas avaliativas utilizadas pelos professores com formação em educação física em Miracema do Tocantins (TO).

\begin{tabular}{|ll|}
\hline Descrição & $\mathbf{n}$ \\
\hline Caderno de registro & 5 \\
\hline Apresentação de trabalhos & 5 \\
\hline Provas & 4 \\
\hline Seminários & 4 \\
\hline Ficha de avaliação & 3 \\
\hline Criação individual (pinturas, desenhos, brinquedos confeccionados) & 3 \\
\hline Estudo dirigido & 3 \\
\hline Resenhas ou fichamentos & 3 \\
\hline Observação & 3 \\
\hline Apresentação cultural & 2 \\
\hline Desenho de autoria do aluno & 1 \\
\hline Portfólio produzido pelo aluno & 1 \\
\hline
\end{tabular}

Fonte: Elaboração própria.

Na análise das fontes, o Quadro 4 destaca que as práticas avaliativas com maior recorrência se apropriam de uma perspectiva de educação física que privilegia os saberes objetos em detrimento de saberes de domínio (CHARLOT, 2000) ou do próprio protagonismo dos alunos em seu percurso formativo (LANO, 2019).

O "caderno de registro", "apresentação de trabalho", "provas", "seminários", "ficha avaliação", "estudo dirigido" e "resenha e fichamentos" são práticas que refletem essa perspectiva da avaliação, que permitem medir (VIANNA, 2000) a aprendizagem dos alunos por meio de um método que forneça a compreensão do conceito ou nota obtida pelo aluno.

Essa ação, na educação física escolar, se remete aos estudos sobre avaliação da década de 1970 (FROSSARD, 2015; SANTOS et al., 2018), podendo ser, nos ditos de Vianna (2000), usada tanto para medir, como para manter o controle sobre os alunos.

É importante compreender quais as intencionalidades de uma prática avaliativa, pois sua utilização está associada ao fazer docente e a própria concepção de avaliação. Nesse sentido, as práticas supracitadas, quando mobilizadas pelo viés da avaliação formativa podem ser usadas (CERTEAU, 1994) como ações que permitam aos docentes, no processo de ensino-aprendizagem, identificarem os problemas da formação e reorganizarem suas ações pedagógicas (BLACK; WILIAMN, 2003), enriquecendo o processo de escolarização.

Já, quando utilizados em uma concepção associada à medida como perspectiva avaliativa (VIANNA, 2000), as práticas (CERTEAU, 1994) podem direcionar para o rendimento escolar, secundarizando as dificuldades de aprendizagens e o protagonismo dos alunos em seu processo de escolarização.

As práticas avaliativas com menor recorrência como "criação individual", "apresentação cultural", "desenho" e "portfólio" sinalizam a utilização de práticas que privilegiam o protagonismo dos alunos e, especialmente, a compreensão daquilo que se faz com o que se aprende (SANTOS, 2005; SANTOS et al., 2015;
2019; VIERA, 2018; LANO, 2019), pois permite aos alunos se envolver no processo de produção do saberes escolares, praticando (e autoavaliando) suas aprendizagens.

Nesse caminho, a avaliação é colocada como ação investigativa (ESTEBAN, 2001), se assumindo como fio condutor do processo formativo na escola, permitindo aos alunos atribuírem sentido as suas aprendizagens, por meio de processos criativos construídos individualmente ou coletivamente.

Dessa forma, o docente pode levar os alunos a autoavaliarem suas aprendizagens, refletindo sobre o processo e quais as táticas (CERTEAU, 1994) usadas para dar visibilidade a elas. Assim, a produção cultura, destacada anteriormente nesse artigo como foco da avaliação, emerge nas práticas dos alunos, como ação autoral.

Não podemos desconsiderar que a educação física é o componente curricular que subverte a lógica escolar (SCHNEIDER; BUENO, 2005), mas ainda assim, ao analisarmos o Quadro 4, percebemos que a forma escolar (BARCELOS; SANTOS; FERREIRA NETO, 2015; 2017), atravessa os afazeres docentes, impactando na materialização da prática avaliativa.

Especialmente, na medida em que se entende o ato de avaliar como ação cristalizada (ESTEBAN, 2001) que não é mutável por estar enraizada na própria compreensão de escola e de como seus componentes curriculares agem.

\section{CONCLUSÃO}

O objetivo desse artigo foi compreender quais práticas avaliativas têm sido utilizadas na educação física escolar no município de Miracema do Tocantins (TO). Para isso, precisamos entender se os professores com formação em educação física tiveram contato com o conteúdo avaliação em sua formação inicial e o que eles avaliam em suas aulas. Essa ação nos permitiu compreender as racionalidades empregadas em suas práticas avaliativas, atravessados pelo movimento autoformativo; o envolvimento e os valores como objetos da avaliação; e a utilização de práticas avaliativas articuladas com os saberesobjeto em detrimento dos saberes de domínio (CHARLOT, 2000).

Foram identificadas práticas avaliativas utilizadas pelos professores com formação em educação físicas inscritas em duas perspectivas, uma associada a medida (VIANNA, 2000), e a outra a prática investigativa (SANTOS et al., 2019).

Essa pulverização nas práticas avaliativas emergem da apropriação (CERTEAU, 1994) de uma cultura escolar em que o saber objeto é privilegiado, produzindo estratégias que sinalizam para os docentes quais práticas devem/podem ser utilizadas, independentemente do componente curricular.

Portanto, destacamos a necessidade de avançar em relação a compreensão do fazer avaliativo na educação física escolar, produzindo práticas que evidenciem aquilo que o aluno faz com o que aprende (SANTOS, 2005; SANTOS et al., 2015; 2019; VIERA, 2018; LANO, 2019), uma vez que a concepção de educação do docente é responsável pelas ações que vão delinear o projeto de escolarização.

Ao assumirmos como lócus da pesquisa um município na região norte do País, nos inserimos em uma das lacunas identificadas por Frossard (2015) e Santos et al. (2018), contribuindo, de certo modo, para a compreensão do fazer 
avaliativo nesse contexto. Evidentemente, o estudo tem limitações como: a quantidade de professores com formação em educação física atuando na cidade; docentes que atuam fora da sua área de conhecimento específico para atender as demandas da educação básica.

Essas limitações impactam, inclusive, na maneira como os docentes mobilizam a avaliação no cotidiano escolar, tensionando aquilo que deve ser seu objeto e os recursos didáticos utilizados para potencializar o processo de ensinoaprendizagem.

Não obstante, a pesquisa contribuiu para a reflexão dos professores com formação em educação física que atuam no município de Miracema do Tocantins (TO), sobre suas práticas avaliativas, especialmente na articulação com o conhecimento compartilhado no cotidiano escolar, entendendo as diferentes práticas avaliativas e como elas podem enriquecer a formação de professores e alunos quando utilizadas a partir da específicidade desse componente curricular.

Sinalizamos como possibilidade de novos caminhos investigativos a necessidade de produção de estudos de natureza etnográfica que permitam analisar aquilo que ocorre no cotidiano escolar, especialmente sobre as práticas avaliativas na cidade de Miracema do Tocantins (TO), região norte do País.

\section{REFERÊNCIAS}

BARCELOS, M.; SANTOS, W.; FERREIRA NETO, A. Aprender na educação física: diálogos com as crianças e a professora. Journal of Physical Education, Maringá, v. 28, p. 1-16, 2017

BARCELOS, M.; SANTOS, W.; FERREIRA NETO, A. Crianças, infância e escolarização: tessituras na transição da educação infantil para o ensino fundamental de nove anos. Motrivivência, Florianópolis, v. 27, n. 45, p. 84-101, 2015.

BLACK, P.; WILIAM, D. In praise of education research: formative assessment. British Educational Research Journal, New Jersy, v. 29, n. 5, p. 62337, 2003.

BOLZAN, E; SANTOS, W. Propostas didático-pedagógicas e suas projeções para o ensino da educação física. Revista da Educação Física, Maringá, v. 26, n. 1, p. 43-57, 2015.

CAPARROZ, F. E. Entre a educação física na escola e a educação física da escola: a educação física como componente curricular. Vitória: CEFD-UFES 1997.

CERTEAU, M. A invenção do cotidiano: artes de fazer. Porto Alegre: Artmed, 1994.

CHARLOT, B. Da relação com o saber: elementos para uma teoria. Porto Alegre: Artmed, 2000

ESTEBAN, M. T. O que sabe quem erra? Reflexões sobre a avaliação e fracasso escolar. Rio de Janeiro: DP\&A, 2001.

FOSCARINI; N. B.; FONSECA, G. M. M. A avaliação na educação física escolar: o discurso dos professores. Caderno de Educação Física e Esportes, Marechal Cândido Rondon, v. 9, n. 16, p. 97-107, 2010.

FROSSARD, M. L. Avaliação educacional em educação física: um mapa da produção acadêmica de 1930-2014. 2015. 167f. Dissertação (Mestrado em Educação Física) - Universidade Federal do Espírito Santo, Vitória, 2015.

LANO, M. B. Usos da avaliação indiciária na educação física com a educação infantil. 2019. 148f. Tese (Doutorado em Educação Física) - Universidade Federal do Espírito Santo, Vitória, 2019.

MENDES, E. H.; BARBOSA-RINALDI, I. P. Avaliação da aprendizagem na educação física escolar: caminhos percorridos e desafios atuais. Caderno de Educação Física e Esportes, Marechal Cândido Rondon, v. 18, n. 1, p. 11923, 2020.
MICHEL, M. H. Metodologia e pesquisa científica em ciências sociais: um guia prático para acompanhamento da disciplina e elaboração de trabalhos monográficos. 3. ed. São Paulo: Atlas, 2015.

OLIVEIRA, A. Etnografia e pesquisa educacional: por uma descrição densa da educação. Educação Unisinos, São Leopoldo, v. 3, n. 17, p. 271-80, 2013.

POLTRONIERI, H.; CANLDERON, A. I. Avaliação na educação básica: a revista estudos em avaliação educacional. Revista Avaliação Educacional, São Paulo, v. 23, n. 53, p. 82-103, 2012.

SANTOS, W. Currículo e avaliação na educação física: do mergulho à intervenção. Vitória: Proteoria, 2005.

SANTOS, W.; FROSSARD. M. L.; MATOS, J. M. C.; FERREIRA NETO, A. Avaliação em educação física escolar: trajetória das produções acadêmicas em periódicos (1932-2014). Movimento, Porto Alegre, v. 24, n. 1, p. 9-22, 2018.

SANTOS, W.; MATHAS, B. J.; MATOS, J. M. C.; VIEIRA, A. O. Avaliação na educação física escolar: reconhecendo a especificidade de um componente curricular. Movimento, Porto Alegre, v. 21, n. 1, p. 205-18, 2015.

SANTOS, W.; VIEIRA, A. O.; MATHIAS, B. J.; BARCELOS, M.; CASSANI, J. M. Avaliação na educação física escolar: analisando as experiências das crianças em três anos de escolarização. Movimento, Porto Alegre, v. 25, p. 1-17, 2019.

SCHNEIDER, O.; BUENO, J. G. S. A relação dos alunos com o saber compartilhado nas aulas de educação física. Movimento, Porto Alegre, v. 11, n. 3, 2005.

TOCANTINS. Documento curricular do Tocantins ensino fundamental: linguagens. Secretaria de educação, juventude e esportes. Governo do estado do Tocantins. 2020. Disponível em: <https://seduc.to.gov.br/publicacoes/ publicacoes/documento-curricular-do-tocantins---educacao-infantil-e-ensino-fundamental/>. Acessado em: 15 de fevereiro de 2020.

VAGO, T. M. Pensar a educação física na escola: para uma formação cultural da infância e da juventude. Cadernos de Formação RBCE, Rio de Janeiro, v. 1, n. 1, p. 25-42, 2009.

VIANNA, H. M. Avaliação educacional: teorias, modelos e planejamento. São Paulo: IBRASA, 2000.

VIEIRA, A. O. Educação física e a pedagogia da infância: leituras das práticas avaliativas por narrativas e imagens. 2018. 320f. Tese (Doutorado em Educação Física) - Universidade Federal do Espírito Santo, Vitória, 2018.

\section{AGRADECIMENTOS}

O autor agradece Universidade Federal do Tocantins, a Diretoria Regional de Ensino de Miracema (TO) e ao Grupo de Investigação Pedagógica em Educação Física (Gipef)

\section{CONFLITO DE INTERESSE}

O autor do estudo declara não haver conflito de interesses.

\section{FINANCIAMENTO}

Este estudo não teve apoio financeiro.

\section{ORCID E E-MAIL DO AUTOR}

Marciel Barcelos (Autor Correspondente) ORCID: 0000-0003-1181-8724.

E-mail: marcielbarcelos@gmail.com 